\title{
JURUPARY ARTICULA O ESPAÇO DOS TÁRIA E A CIÊNCIA DA AMÉRICA TROPICAL
}

Desde a sua publicação em 1890, a 'lenda' do Jurupary na versão italiana de Stradelli tem provocado as reações mais diversas, quando não contraditórias. Por um lado, o texto é reconhecido como uma obra prima cosmogônica, de grande sofisticação literária, comparável com o Popol vuh da Mesoamérica. Por outro lado, foi criticado como pretencioso, literário no mau sentido da palavra, e no melhor dos casos como apenas um fator secundário no 'complexo' mítico do Jurupary e das culturas representadas por este personagem.

De toda a forma, a Leggenda ${ }^{1}$ do Conde Ermanno Stradelli permanece como um dos primeiros textos a oferecer uma versão extensa e bem articulada do gênesis amazônico. Ele parte da experiência específica dos tária e de outros grupos assentados nos rios Uçana e Uaupés, na região geral do Rio Negro onde é mais conhecido o Jurupary, para elaborar um verdadeiro esquema das origens, que atinge tanto práticas culturais como os movimentos do cosmos.

\section{Características do texto}

Não há dúvida de que a Leggenda no italiano de Stradelli resultou da tradução de outro texto prévio coletado pelo indígena da região Max Roberto e escrito por ele na língua geral nheengatu, o qual agora se crê perdido. Também é seguro que a versão nheengatu teria tornado patente a complexidade linguístico-cultural da região, sobretudo com respeito ao tucano falado pelos tária, grupo originariamente arauaco ao qual pertence este relato do Jurupary e com o qual colaborou Max. Outros exemplos do trabalho em nheengatu de Max, sobrinho do tuxaua tária e de um índio manau, lou-

(*) University of Essex, Inglaterra; Stanford University, EUA. (1) Leggenda dell'Jurupary, Stradelli 1964. A tradução ao português, editada por Ségio Medeios, vai aparecer em 2001 pela Editora Perspectiva, São Paulo. vado por todos os que o conheciam e que trabalharam com ele, sobrevivem em publicações feitas por Barbosa Rodrigues e Brandão de Amorim, e pelo próprio Stradelli, nos seus Vocabulários de 1929.

Quaisquer que sejam as interferências literárias feitas pelo Conde Stradelli em nome do 'bom gosto' do século passado, a Leggenda publicada por ele tem propriedades chaves que dificilmente se poderiam atribuir apenas à sua invenção. $\mathrm{O}$ texto possui uma assombrosa riqueza léxica, comprovada até mesmo pelos nomes próprios, que apela tanto ao nheengatu de Max como ao tucano, ao arauaco, e às outras falas dessa região intensamente multilíngue. O nome alternativo da primeira Seucy, Meenspuin, remete à sua ascendência cubeua, enquanto que o do seu irmão Pinon é tucano. $O$ nome Ualri, que identifica o personagem encarregado da construção da maloca ocidental do Jurupary no rio Aiary, tem significado precisamente na língua arauaco daquele lugar (o baniwa) e quer dizer tamanduá, animal cujo suposto comportamento libidinoso aponta para o do próprio Ualri. Como para confirmar esta ordem de federalismo linguístico, Jurupary escolhe termos respectivamente de mais de dez falas e dialetos locais ao batizar os vários instrumentos do seu culto (pp. 41-2).

Além disso, o texto tem uma estrutura tão habilmente elaborada que a sua sutileza escapou a mais de um crítico. Técnicas xamânicas permitem a certos personagens (e por isso, ao leitor) saber o que está acontecendo em outra parte, produzindo narrativas paralelas (pp. 27, 45-6). Marcos sucessivos contêm a história central de Pinon e os níveis de tempo nela implícitos (pp. 30-40). Também é usada a técnica da identificação adiada: só com base em pistas ocultas espalhadas pela narrativa pode o leitor reconstruir a verdadeira genealogia de Jurupary e saber que a sua mãe, a Seucy terrestre, filha de uma das mulheres fecundadas no lago Muypa, tem que ser idêntica à Jacy Tatá, fillha de Pinon e a estrela matutina (isto é, Vênus): 


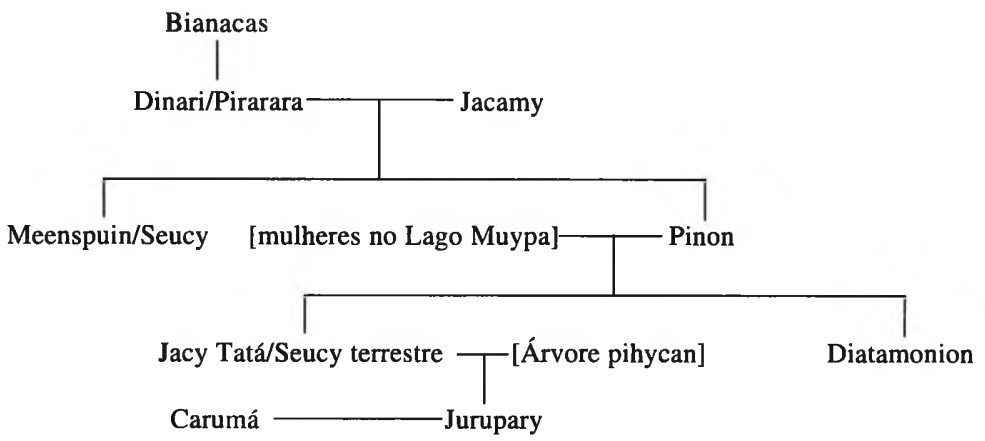

Tais são as indicações que dá Jurupary ao terminar de contar a história de Pinon, ${ }^{2}$ as quais são corroboradas numericamente pelo fato de que as gravidezes da linha genealógica que une a mãe de Pinon (Dinari) à mãe de Jacy Tatá e à mãe de Jurupary são medidas cada uma como dez luas (dieci lune). Esta complexidade vem acompanhada também de uma certa reflexividade, de uma auto-consciência na qual o texto se constrói à medida que constrói o mundo dos tária.

É de suma importância lembrar que foram precisamente estas qualidades literárias do texto que levaram Lévi-Strauss a excluí-lo do seu estudo compreensivo da mitologia oral da América do Sul, Mythologiques, e a insinuar que esta ordem de sofisticação poderia ter que ver com a longa e rica tradição arqueológica da região. Mais recentemente, Patrice Bidou (1989: 65-6) cita esta opinião de Lévi-Strauss para fundamentar o seu próprio estudo da complexidade formal da Leggenda, enquanto que a arqueologia está provendo datas para a cerâmica do Uaupés que remontam a até 3000 anos. $^{3}$

\section{A dimensão geo-histórica}

O motivo ostensivo da história do Jurupary é bem reconhecido. A sua ressonância social e polí-

(2) 'Pinon...fu il secondo paié del mondo. L'ultimo giorno ch'egli stette sulla terra, fu quello in cui fecondò le vostri madri, da cui pure discendo' (p.40). A associação entre a sua filha Jacy Tatá ou Vênus e a 'Seucy della Terra', filha do pajé que fecundou as mulheres no lago Muypa, é corroborada pelo fato de que ela chegou 'all'età dei primi amori tanto pura come la stella del mattino' [isto é, Vênus] (p.16). (3) Neves 1997. Devo a Eduardo Neves vários dados e uma orientação geral com respeito às culturas do Uaupés. tica na região do Içana-Uaupés foi amplamente comentada, sobretudo no sensível e erudito estudo de Hugh-Jones (1979). No caso do texto de Roberto-Stradelli, a vida do herói Jurupary dá validade a certos privilégios masculinos dentro da sociedade tária. A partir de desajustes demográficos entre homens e mulheres, surgem brigas e complicações endógamas que envolvem outras tribos e são finalmente resolvidas graças ao exemplo político do Jurupary e às regras ('leis') que emite, relativas ao comportamento social e à prática especializada da música. ${ }^{4}$ Este é um tema muito generalizado na América indígena, elaborado em textos de povos tão distantes como os navaho de Anasazi e os selknam da Patagônia, e que recebe aqui um tratamento distintivo por parte dos que inventaram o Jurupary, sendo implantado no detalhe geo-histórico daquela região (Hill 1993). Desta forma, ouvimos sobre as serras Tenui (lar dos tária), Canuke, Duba e Marubitena; os lagos Muypa, Cudiary e Micura; os rios Aiary, Içana, Uaupés e Caruma; as cachoeiras Nosque Busca e Jurupary; as terras e malocas dos Nunuiba, Cudiacury, Bianacas, Ilapay e Naruna.

Por sua parte, Câmara Cascudo explica como o Jurupary serve de fundamento político para a carreira subseqüente de Buopé, que lega o seu nome ao rio e ao povo chamado Uaupés no Brasil e Vaupés na Colômbia. Depois de uma série de atividades militares, este Buopé estabelece os três centros tárias em Jauarete, Ipanoré e Taracuá, e funda a linha de tuxauas à qual pertence, nove gerações mais

(4) O significado dos instrumentos de Jurupary, notado já por A.R.Wallace no seu Travels on the Amazon and Rio Negro (Londres 1853), constitui o tema principal do estudo de Hugh-Jones (1979) . Os comentários de Hugh-Jones foram importantes para a preparação do presente artigo. 
tarde, Max Roberto. A estratégia e os detalhes precisos correspondem ao que o texto dos vizinhos desana, Antes o mundo não existia (Umasin 1995), nos diz dos assentamentos do Uaupés e do papel dos fundadores 'trovões' termo equivalente a 'tária' Câmara Cascudo também nos ensina a deduzir do texto da Leggenda referências ao âmbito maior da história do Jurupary, para localizá-la num território que hoje abarca a Venezuela ao leste e os estados andinos no oeste.

Examinando o texto e lembrando a lógica da sua estrutura, vemos de fato que propõe dois modelos geo-históricos, um em escala local (p. 20) e outro em escala mais ampla (p. 38), que derivam dos elos maternos que caracterizam respectivamente a Jurupary e ao seu ancestral Pinon. No primeiro caso, a mãe de Jurupary, petrificada graças à ação do próprio filho, fica como sinal definitivo do território tária. Com a cara voltada para o leste, estende a mão 'do coração' ou esquerda para o norte e o lago Muypa, onde se banhava a constelação das Plêiades e onde foi concebida a própria mãe. Estende a outra mão para o sul e para a árvore da fruta pihycan, onde ela concebeu Jurupary. Modesto mas preciso, este modelo dá um significado muito útil ao espaço da antiga história tária, além de estabelecer uma série de oposicões direcionais e lógicas e permitir uma correlação com o segundo modelo, o de Pinon.

Apesar de toda a preocupação de Pinon, sua mãe abandona a família depois de o seu marido Jacamy ser morto pelos próprios filhos (Pinon e Seucy), e viaja para longe, até as montanhas altíssimas do ocidente. Desesperado por não poder encontrá-la, Pinon organiza uma série de expedições que partem do centro mesmo do território, o momento equatorial no curso do Uaupés onde não se tem sombra ao meio-dia. Num desenho feito para este propósito, define as direções que se deveriam seguir, ou seja, as quatro do modelo da mãe de Jurupary, mais outras quatro intermediárias. Cada um dos oito roteiros que saem do centro deve ser seguido por uma equipe de cinco homens casados, e a configuração total é chamada de a dos 'cepos do mundo'. Mais tarde saem expedições de mulheres, nove no total, sendo todos estes números pertencentes à definição celestial do espaço.

Estes modelos, tão claros na experiência de Jurupary e de Pinon, ajudam a compreender o seu território como intermediário entre montanhas orientais e ocidentais. Jurupary termina seus dias nas primeiras, quando vai à procura da aurora, e sua companheira Carumá vira lago e rio. Nesta área se levantam as serras de Pacaraima que se estendem até Roraima, a anexa geografia intimamente descrita em Watunna (Civrieux 1992), gênesis caribe dos makiritare que lembra repetidamente a da história de Jurupary, e que menciona um lago (Akuena) com as qualidades restaurativas do de Carumá. A continuidade cultural do território tária com estas regiões orientais é facilmente comprovável numa comparação entre a Leggenda e clássicos de Pacaraima como Watunna. Em ambos encontramos a árvore que conectava céu e terra, a lua masculina e incestuosa, a visão privilegiada do pajé ou xamã, metamorfoses incessantes, cachoeiras mágicas, e muito mais.

Chamadas de 'a serra das pedras brancas' as montanhas do oeste são tão altas que parecem tocar o céu: é lá que Pinon encontra a passagem ao céu para a sua irmã Meenspuin; e é lá que é transformada em outro lago a sua mãe perdida. ${ }^{5}$ Estudos prévios já detetaram vestígios andinos na história de Jurupary, entre eles a sua atuação como herói patriarcal e solar que anda pela paisagem dispensando leis ao estilo de um Viracocha inca ou um Bochica chibcha, notavelmente na cena depois da 'orgia', quando obriga um dos seus a se casar com a mulher que violara. Outros indícios incluem a casa para mulheres que inaugura segundo o modelo do accla huasi inca, e a aguda preocupação que tem Pinon com a virgindade da sua irmã Meenspuin. Num plano americano, esta ordem de protecionismo e supremacia masculinos parece estar intimamente ligada à economia e à ideologia do pastoreio, fenômeno limitado aos Andes antes da chegada de Colombo.

Ainda mais eloquientes são certos detalhes aritméticos e calendáricos que dificilmente poderiam ter outra origem. A base numérica usada para contar os anos da busca da mãe de Pinon $(1,2,10$, muitos) é claramente decimal, como era a da aritmética inca e chibcha, diferentemente das bases binária e vigesimal mais caractéristicas da Amé-

(5) Em termos zoológicos, o âmbito cultural protagonizado por Jurupary corresponde ao habitat da ave que era o seu bisavô, o jacamy ou 'pássaro trombeteiro' (Psophia; ver abaixo), o qual se estende da Guiana até os Andes, sempre ao norte do Amazonas. Agradeço a David Attenborough a amabilidade de ter compartilhado os seus vivos conhecimentos sobre esta ave. 
rica tropical (Closs 1985): entre os caribe de Pacaraima e os maia da Mesoamérica, por exemplo, a palavra para homem é sinônima do vinte dos seus dedos da mão e do pé. Como veremos, o princípio decimal na Leggenda até se combina com o contar das fases da lua sideral, outro diagnóstico do calendário inca. Em outro momento, os cinco homens mandados a Aiary (entre eles Ualpi) para construir a maloca de Jurupary cumprem esta tarefa em três dias, o equivalente a quinze dias de trabalho. Assim deixam livres outros quinze dias, período conhecido como o 'meio mês' Segundo o testemunho de vários textos de Tahuantinsuyu, este mesmo período era diagnóstico do calendário imposto pelos inca. Ao falar da sujeição das tribos da floresta tropical e da função que tiveram nela cálculos feitos nos cordéis do quipu, a peça de teatro quechua Ollantay faz exatamente a mesma definição do número calendárico quinze. A partir destes indícios é legítimo ver na Leggenda reminiscências andinas do tipo que tão abundantemente aparecem em outros textos da Amazônia ocidental, por exemplo entre os campa, os shipibo-conibo, e até entre os guarani do Paraguai. ${ }^{6}$ Reichel-Dolmatoff (1971: 253) transcreve um relato desana sobre como chegaram ao Uaupés as técnicas andinas da ouriversaria.

Ao relatar o 'mito' de Jurupary e ao constatar a sua importância sincrônica e simbólica, o texto traduzido por Stradelli não deixa por isso de localizá-lo firmemente num espaço que compreende a história mais e menos recente dos tária.

\section{O entendimento das formas vitais}

Ninguém soube melhor que Reichel-Dolmatoff pesquisar o meio ambiente que une Jurupary, Watunna, Antes o mundo não existia e vários ou-

(6) No contexto cultural estabelecido por Lathrap (1970), a questão dos contatos com os Andes aparece em Brotherston 1997: 450-451, que também toca (p. 259) na imposição do 'meio mês' inca - chicta quilla -, segundo a Nueva corónica de Guaman Poma (1613) e o Manuscrito de Huarochiri (1605). R.T. Zuidema aborda o tema do mês sideral em 'Catachillay: The Role of the Pleiades...in the Calendar of the Incas', Aveni \& Urton 1982: 203-230; e em 'Towards a General Andean star calendar in ancient Peru', Aveni \& Brotherston 1983: 235-60. Para o caso dos machiguenga, ver Sá 1997. Viajantes do século 18 viram tárias ornamentados de ouro no estilo andino (Orjuela 1983: 33). tros textos que provêm daquela parte da América tropical $(1971,1989,1996)$. É lendária a sua capacidade para revelar as lógicas e epistemologias cifradas em relatos que aparentemente aludem só de passagem às vidas das plantas, dos insetos e dos vertebrados. No caso de Jurupary, ele se sobressai ao expor os profundos elos entre a vida sexual das palmeiras, forma terminal que assumiu Ualpi, e os costumes e a imaginação tárias; fala também de elos ainda mais cósmicos, entre estas mesmas árvores e as Plêiades, matéria que deu título ao livro de Hugh-Jones, The Palm and the Pleiades. Ainda que se concentre em versões paralelas da história do Jurupary, para ele mais próximas da imaginação indígena, Reichel-Dolmatoff descobre toda uma série de conexões deste tipo também na Leggenda de Stradelli. A própria densidade da sua leitura biológica nos anima agora a continuá-la, respeitando em primeiro lugar o conjunto de referências textuais ao conceito da reprodução dos vertebrados.

No relato do Pinon, cujo marco formal é definido pelo fato de ser contado, num momento dado da Leggenda, pelo próprio Jurupary, o enfoque biológico neste sentido é a família nuclear a que pertence este personagem. O pai do Pinon é um dos Jacamy, povo de aves loquazes, altamente domesticáveis, e leais no afeto, que tem os seus próprios costumes e até parlamento: são os jacami da familia Psophia, também chamados de agami ou aves trombeteiras. Ao casar com ele, a mãe Dinari ('ave preta') assume também a forma de uma ave jacami, e quando fica grávida eles preparam um ninho para os futuros filhos. Mas ao começar a dar à luz sente dores anormais e readota a forma anterior, explicando que não é anatomicamente capaz de "parir" ovos. Ainda assim, os filhos gêmeos saem como ofídios, o sucuri Pinon e sua irmã Meenspuin, 'fogocobra' Ao final do episódio a mãe Dinari recebe uma identidade e um nome definitivos, o da "piraarara' ou peixe-ave (arara), que amplia os termos do mesmo registro zoológico. Porém, este episódio da família de Pinon estabelece relações genéticas entre os que na sucessão evolutiva são os vertebrados peixe, ofídio e ave, e explicitamente toca na distinção entre ovíparos e vivíparos; e a genealogia estabelecida desta maneira continua na história dos mamíferos e humanos protagonizada por Jurupary.

A filha de Pinon é a mãe de Jurupary. Concebe-o quando lhe entra na vagina o suco da fruta pihycan jogada ao chão por alguns macacos, que nas versões paralelas se masturbam para substituir 
o suco pelo próprio esperma (Bidou 1989: 88). Dado o antecedente tão explícito dos ofídios-aves da família de Pinon, não é dificil ver aqui a continuação do relato evolutivo, no qual, concebido graças à partenogenesis, Jurupary chega a uma condição superior à dos macacos, para anunciar a história propriamente humana que começa com o primeiro tuxaua Buopé.

Pela sua própria extensão e articulação, a Leggenda de Stradelli torna patente um argumento firmemente evolutivo enquanto à ascendência vertebrada dos humanos e dos tuxauas tárias. Ainda mais, se os nascimentos de Pinon e de Jurupary representam cada um novos começos nesta história devidamente pontuados pela estrutura do texto, é possível saber de outros começos anteriores mais antigos, coevos com os princípios mesmos do mundo. Isto ocorre, por exemplo, quando Pinon e a sua irmã, gigantes que também têm a natureza estelar das constelações de Scorpius (o sucuri) e das Plêiades, se deleitam criando e abatendo montanhas inteiras, o que faz com que o povo de Dinari se lembre das grandes catástrofes da primeira terra, quando nasceu o mundo ('era un fatto non ancora visto da che era nato il mondo'; p. 35). Aqui a Leggenda adiciona fatores geológicos e astronômicos ao discurso zoológico tipificado pelo sucuri Pinon e, bem estudada, descobre um relato de sucessivos começos que em princípio abarcam desde a formação física da terra até a institução da política humana.

Este arranjo tem múltiplas ressonâncias na literatura não só do cosmos amazônico (para usar o termo de Reichel-Dolmatoff), mas de toda a América tropical. De fato existe uma assombrosa coincidência com o esquema clássico elaborado nos textos dos Andes e da Mesoamérica onde um conjunto de quatro 'sóis' ou idades do mundo é inerente à nossa época, cada um caracterizado pelo tipo de seres que viviam neles e pelas suas catástrofes terminais. Os paralelos mais dramáticos são com a literatura da Mesoamérica, com os códices (livros pré-hispânicos) e vários textos escritos desde o século XVI nas línguas maia e nahuatl (Brotherston 1995), num contexto já indicado pelas muitas coincidências culturais bem eloqüentes, ainda que pouco reconhecidas. A árvore amazônica de frutos diversos que uma vez conectou céu e terra aparece como emblema cósmico no tonalpoualli (calendário ritual dos códices) sob o nome 'Tamoanchan' A narigueira de jade que enobrece e protege Jurupary fez o mesmo para heróis dos anais como Oito Veado, con- quistador mixteco do século XI; e os claramente definidos tipos de voadores que tira Jurupary da sua resina sagrada (p. 18) ou que atuam como personagens-noturnos, de penas vistosas, de dieta vegetariana, de rapina, comestíveis, domesticáveis, loquazes etc. - correspondem diretamente outra vez aos do tonalpoualli. O quartzo adivinhatório, $\mathrm{o}$ 'sêmem celeste' amazônico, tem uma definição comparável ao ser reverenciado como força vital no Popol vuh, a celebrada 'bíblia americana' dos maia-quiché. $O$ machado que trabalha sozinho e a construção da primeira casa que leva a uma embriaguez de três dias são igualmente temas comuns.

A comparação entre a Leggenda e este outro testemunho literário da América tropical nos ajuda a perceber a coerência do argumento que aquele texto propõe sobre os vertebrados e o fato de que isto não é nada fortuito ou isolado. No seu relato de metamorfoses incessantes e de seres proteicos, por alucinante que apareça, é certo que existe um propósito firme e lógico. A afinidade especial que tem a Leggenda com o Popol vuh maia já foi notada por Orjuela (1983), para ser depois contradita pelo seu compatriota Reichel-Dolmatoff (1987: 97), no que parece ter sido um acesso de mau humor. ${ }^{7}$ Levando em conta o esquema de sóis ou idades tal como fica estabelecido em textos como a Pedra do Sol e os Anais de Cuauhtitlan (Brotherston 1997: 303-334), de fato se pode afirmar esta afinidade mediante a seguinte análise estrutural:

\section{Quando nasceu a terra}

$1^{\mathrm{a}}$ e $2^{\mathrm{a}}$ idades (dilúvio e eclipse; primeiros vertebrados)

catástrofes de primeira ordem

terra sacudida pelo impacto de objetos atirados do céu

Família Jacamy e esposa, mais fillhos Pinon e Meenspuin

$3^{\mathrm{a}}$ idade (chuva de fogo; família Sete Papagaio e esposa, mais filhos Cipacna e Cabracan)

(7) Reichel-Dolmatoff continua com a mesma abordagem no seu estudo mais detalhado e póstumo de 1996, que inclui e examina quatro textos tukanos relevantes ao 'foundation myth' do Jurupary. Nas suas referências ao Popol vuh, Orjuela (1983) percebe bem a escala cósmica de ambos os textos e sugere paralelos com respeito ao fruto da árvore que engravida (p. 172) e às aventuras épicas dos Gêmeos (p. 151). Mas não chega a tocar nos temas genéticos dos símios e das metamorfoses. 
- família nuclear de pais que são aves domesticáveis e loquazes, e dois filhos ofidios/ sáurios

filhos gigantes (sucuri; jacaré) que têm força para poder formar e arrasar montanhas inteiras

- filhos também torcem a rocha no estilo da ação vulcânica

episódio que corresponde à origem das Plêiades; formalmente inserido no relato seguinte

\section{Epopéia do herói Jurupary (e Caryda)}

$4^{\mathrm{a}}$ idade (vento; epopéia dos heróis Gêmeos).

nascimento partenogenético a partir da fruta de uma árvore interdita, localizada no sul/ em baixo

- diferenciação genética dos 'irmãos mais velhos' macacos

viagem até o inframundo ('meio da terra'/Xibalba)

reduzem as sombras danosas e sádicas dos mortos

- sobrevivem graças à capacidade xamânica de se metamorfosear e se comunicar com outras espécies

sabem da solidariedade e da ajuda mútua; são músicos

afiliação solar ao ensinar as regras do comportamento social e anunciar a época atual

A maior parte dos detalhes paralelos são patentes, como o é a organização geral. O discurso zoológico sobretudo exibe em ambos os casos uma coerência que merece mais atenção do que até agora recebeu. Reivindica os parentescos e a verdadeira natureza do tão citado Quetzalcoatl, Gucumatz no Popol vuh, o ofidio-ave que, jazendo nas águas primordiais, já contém e prefigura a história evolutiva que elaborou a América muito antes de que Darwin a intuísse. Não só neste caso, é notável o gosto por nomes duplos cujos termos em si supõem todo esse argumento: a peixearara (Pirarara), mãe de Pinon e Meenspuin; a jacaréarara (Cipacyalo), madrasta dos Gêmeos; os homenspeixes (uiniq kar), forma a que revertem os Gêmeos (cf. os tlacamichin dos nahua); o jaguar-veado (Ixbalanque), um dos Gêmeos. O mesmo pode se dizer das metamorfoses múltiplas dos heróis épicos (JuruparyCaryda/os Gêmeos) e dos que eles perseguem, as quais ontologicamente recapitulam ao inverso o processo evolutivo, estabelecendo também a linha alternativa dos insetos (pp. 55-6). A grande afinidade que tem a Leggenda com o Popol vuh consiste em que em última instância ambos os textos foram escritos por autores 'nobres' indígenas (Roberto; os Cavek) que estão argumentando a favor de uma ascendência específica, fundando direitos políticos contemporâneos numa longuíssima experiência genealógica. Em ambos os casos, como resultado disto é deixado um pouco de lado o extenso relato dos dilúvios e das escuridões das primeiras idades que tanta importância tem em outros textos da Mesoamérica, da Amazônia (Watunna; Antes o mundo não existia) e dos Andes (Manuscrito de Huarochiri).

\section{Questões matemáticas e astronômicas}

Repetidas vezes, a narração de Jurupary conservada por Stradelli oferece dados numéricos e técnicos que, considerados em conjunto, sugerem uma ordem de conhecimento comparável em certos aspectos com a matemática $\mathrm{e}$ a astronomia presentes nos textos mesoamericanos e andinos, e que até as iluminam, reciprocamente. $O$ fato de que $o$ texto identifique 5 (trabalhadores no Aiary) com 15 (unidades de trabalho; p.20) lembra a prática xamânica de contar não em série senão cumulativamente, segundo a qual 5 é $15(1+2+3+4+5)$. $O$ fato de que Pinon e Meenspuin amadureçam em 18 meses e não anos (p.36) lembra outra prática xamânica americana, a de usar cifras (aqui, duas vezes 9) para mover entre dimensões de tempo. Com respeito à astronomia, os personagens podem ter ou assumir identidades celestiais, como vimos: Pinon e Meenspuin viram as constelações Scorpius e Plêiades, Jurupary atribui a si mesmo qualidades solares, e recebe as suas insígnias de Renstalro, o lua masculino. Ao chegar à sua máxima altura heliacal, o planeta Vênus marca a hora de sair para a expedição ao rio Aiary; em outro momento é identificado com Jacy Tatá, a filha de Pinon que deu à luz Jurupary. São cuidadosamente especificados os momentos significantes no curso destes corpos celestiais, isto é, nos horizontes leste ou oeste e sobretudo no exato meio do céu, modelo típico dos trópicos americanos e categoricamente distinto do das latitudes extratropicais onde nasceu a astronomia polar da Europa.

Definidos pelas suas fases e pela sua presença no zênite e nos horizontes leste e oeste, os períodos sinódicos dos corpos mais brilhantes do céu são confirmados pela aritmética das expedições organizadas 
por Pinon e pelo modelo do espaço segundo o qual ele procura a mãe perdida: o dos 'cepos do mundo' Cinco grupos de homens casados saem do lugar onde Jurupary não tem sombra (o equador) e vão por oito caminhos, o que lembra o fato de que 5 anos sinódicos de Vênus são iguais a 8 anos sinódicos do sol. ${ }^{8} \mathrm{O}$ mesmo roteiro é seguido depois por nove grupos de mulheres, que lembram as 9 luas sinódicas da gravidez, e as 9 gerações de tuxauas estabelecidas por Buopé. As cifras e as fórmulas que reúnem estes três períodos sinódicos, relativos a Vênus, sol e lua, são básicas nos códices e na cultura mesoamericanos. Também os dados de genealogia de Jurupary nos lembram a distinção entre a lua sinódica de 29.54 noites e a lua sideral de 27.33 noites, que é fundamental à astronomia tanto da Mesoamérica como dos Andes. Zuidema nos informa sobre a aritmética decimal dos inca que produz uma gravidez de luas que são 10 (siderais) e não 9 (sinódicas).

É especialmente rica e sugestiva a elaboração das imagens relativas à Via Láctea e às constelações representadas por Meenspuin e Pinon, as Plêiades e Scorpius. Inconfundíveis no céu, cada uma tem a forma que têm respectivamente as estrelas nos corpos de Meenspuin - um cacho na fronte - e de Pinon - uma cobra vertical, da fronte até o pé. Assim, identificam os momentos onde se entrecruzam os dois grandes circuitos do céu: o zodíaco ou plano do sistema solar (a Eclíptica) por onde viajam os planetas, o sol e a lua; e a Via Láctea, aliás o plano da nossa galáxia, que tem o seu berço nas nuvens estelares de Scorpius e Sagitarius. Estes circuitos e os seus dois cruzamentos são perfeitamente observados e conceitualizados como tais na cultura do Uaupés, que também reconhece a oposição entre uma Plêiade fêmea e um Scorpius macho (Reichel-Dolmatoff 1982; Hugh-Jones 1982).

Já no começo da Leggenda se diz que as Plêiades, na personagem que depois descobrimos ser Meenspuin, têm o costume de se banhar no lago

(8) O período sinódico se refere ao movimento de um planeta (sol, lua, Vênus etc.) com relação aos horizontes ou ao zênite; o período sideral se refere ao movimento dos mesmos corpos com relação às estrelas fixas. Cálculos deste tipo aparecem nos códices Dresde e Féjerváry, como notou Eduard Seler faz mais de um século. No texto do Stradelli, a acumulação de números desta ordem em si indica para a Amazônia tanto uma matemática como uma astronomia mais complexas do que é indicado no estudo básico de Closs (1985). Por sua parte, Bolens (1967) fala da multiplicidade semântica das Plêiades na lenda de Jurupary.
Muypa, que fica ao norte. Isso corresponde à idéia de que essa constelação, que estando na curva norte da Eclíptica passa ao norte do equador, se reflete no lago. De lá, segundo a mesma lógica de reflexões, Meenspuin começa a puxar detrás de si a faixa branca da Via Láctea ao mover-se pelo lago. Esta posição inaugural, perto do cruzamento da Eclíptica com a Via Láctea, é atribuída às Plêiades por toda a Amazônia, fato celebrado por LéviStrauss quando categoriza como o seu 'Mito l' as histórias daquela região que narram a origem desta constelação primária. A substância que utiliza Meenspuin para formar a dita faixa branca provém do corpo do pajé em quem depois reconhecemos o seu irmão Pinon. Como a constelação 'sucuri' ou Scorpius, este personagem também pertence à Via Láctea, assinalando a área de maior brilho e densidade de nuvens estelares, sinônimos do seu berço e do centro galácteo. Na verdade, complementa perfeitamente a posição inicial da irmã, no sentido em que fica no extremo oposto, perto do outro cruzamento da Via Láctea com a Eclíptica.

Bem específico e reconhecido em outras culturas amazônicas, este modelo de complementaridade entre as Plêiades e Scorpius, Meenspuin e Pinon, implica toda uma filosofia de interação entre céu e terra. Os barasana, por exemplo, utilizam-no para sincronizar a roça e a colheita, e repetindo a identificação de Scorpius com 'a cobra de Jurupary' (he hino) falam da sua metade do céu noturno como 'venenosa', diferente da das Plêiades, que traz as chuvas. Por sua parte, os kogi da costa caribenha também constatam o mesmo modelo, dividindo todo o céu noturno em metades definidas por estas duas constelações chaves. ${ }^{9}$ As duas constelações reocorrem até mesmo nos códices mesoamericanos, só que agora, firmemente no outro hemisfério, elas trocam de sexo, nas pessoas dos Muitos (as Plêiades que determinaram a

(9) Segundo Hugh-Jones (1982:191), os barasana identificam a constelação, Scorpius, com 'o sucuri [=Pinon] de Jurupari'. Na sua apresentação no XLV Congreso Internacional de Americanistas, 'Astronomia de los kogi' Juan Mayr recorre ao trabalho de K.T. Preuss para confirmar o papel chave, nesta cultura, das Plêiades (Uha) e de Scorpius (Ahu; também conhecido como a cobra Tarvi). Neste caso, como em outros da América do Sul, os paralelos com os códices incluem o fato de se reconhecer uma metade do céu noturno como povoada por bichos venenosos, e de a soma de suas constelações constituir um total de onze (Brotherston 1997: 100-102). 
hora do Fogo Novo) e de Citlalicue/Saia de estrelas (as nuvens galácteas de Scorpius que auspiciaram a irrigação e as boas colheitas). Neste contexto, é possível aduzir evidências da América do Sul para melhor detectar nos códices divisões análogas do céu noturno em metades mais ou menos venenosas.

Reciprocamente, as fontes mesoamericanas informam sobre o total curiosamente exato - 17 de mulheres fecundadas por Pinon depois da sua atuação como o sucuri estelar (Scorpius), perto da aldeia de sua mãe. Este mesmo total aparece na grande festa da fecundação Tlaxochimaco, quando as noites do começo de julho são dedicadas ao sexo e à procura de sementes de flores (xoch-itl), 17 no total, fazendo a conexão implícita entre estas e as nuvens galácteas de Citlalicue (Scorpius), que dominavam o céu à meia-noite precisamente naquele momento do ano. ${ }^{10}$ A natureza estelar do própio Pinon e a sua identidade com Scorpius se associa com o fato de a sua mãe ter sido fecundada deitada, com a cara olhando para o céu noturno.

Graças ao trabalho de campo de Hugh-Jones, torna-se altamente sugestivo o paralelo entre os relatos tária e barasana da dupla Plêiades-Scorpius, enquanto estes definem metades do 'caminho' da Via Láctea. Segundo Hugh-Jones, as metades da Via Láctea barasana correspondentes são conhecidas respectivemante como 'nova' (mama ma) e 'velha' (buku ma - a metade também 'venenosa'); e ainda que agora a Plêiades inaugurem a metade 'nova' antes não era assim, sendo novo o que agora é velho ('The Old Path is said to have come into being before the New but today it is the New Path that precedes the Old in the annual cycle' 1982: 185). Isto lembra precisamente a oposição entre o velho e o novo que se faz com respeito a Pinon e à origem da Via Láctea, no texto de Stradelli. Porque a substância branca que deixa Pinon no lago Muypa, e que Meenspuin puxa atrás de si para formar a Via Láctea, é primeiramente o pó que cobre um corpo de velho, mas acaba sendo sêmem de jovem. Isto é, quando Pinon mergulha no lago depois de Meenspuin, vemos o mesmo tipo de relação cronológica entre as metades da Via Láctea representadas pelas constelações Scorpius

(10) Os nomes de cada uma das 17 flores pintadas no Códice Borbônico (p. 28) são dados em nahuatl no Códice Florentino (livro 2), na festa correspondente; a conexão com Citlalicue é sugerida no mesmo Borbônico (pp. 28, 36), e também em Magliabechiano (f. 44) e possivelmente Borgia (p. 31). e as Plêiades. Não só isto, senão que o lugar onde ocorre a transição possui uma especificidade geográfica, no norte, posição relativa que agora ocupam as Plêiades mas que antes era ocupada por Scorpius.

Astronomicamente falando, as constelações das Plêiades e de Scorpius nunca deixam de presidir os dramáticos cruzamentos da Eclíptica com a Via Láctea. Mas com o tempo trocam de posição uma em relação à outra, graças ao fenômeno conhecido como a Precessão dos equinóxios, que é produzido pela leve diferença entre $o$ ano das estrelas (de 365.256 dias) e o ano do sol ou da agricultura (de 365.242 dias). Agora Meenspuin se banha no lago de Muypa, isto é, as Plêiades são refletidas desde a sua posição mais alta ao norte ao iniciar o ano agrícola, o que entre os barasana é iniciar o 'caminho novo'. Em outras épocas é Pinon que se banha assim, isto é, no passado Scorpius era refletido desde a sua posição mais alta ao norte, e voltará a ser refletido assim no futuro. ${ }^{11} \mathrm{Em}$ termos da história da cultura humana, o ciclo precessional é longo, e Pinon substitui Meenspuin como iniciador do caminho e do ano só depois de quase 13.000 anos. Sem dúvida será por esta razão (se não por ignorância) que quase nunca se faz menção do ciclo precessional na literatura antropológica e arqueológica sobre o Uaupés. Por outro lado, o seu efeito prático se faz rapidamente sensível num calendário agrícola do tipo que se usa no Uaupés, que engrena dia por dia o ritmo das estações agrícolas com o das estrelas, a palmeira com as Plêiades; que faz (com respeito à lua) uma clara distinção entre o tempo sinódico e o tempo sideral; e que no espaço conceitualiza perfeitamente os circuitos da Eclíptica, da Via Láctea e do equador celeste e terrestre. ${ }^{12}$ No tempo da dinastia de Buopé, Meenspuin

(11) Esta oscilação, cada metade do 'grande ano' da Precessão, poderia parecer prefigurada no período de 18 meses, isto é, ano e meio, no qual Pinon e Meenspuin 'amadurecem' Por sua parte parte, Reichel-Dolmatoff nota que para os Desana 'the cycle of fertilizing forces emanating from the sky is punctuated by the shifting of the Milky Way' aliás duas cobras entrelaçadas; e que o seu ritmo é conscientemente correlacionado com o do Equador celeste, implicando numa noção da Precessão: 'At these times of the year, and during the nightly shifting of the Milky Way, the Indians transfer the image of the two snakes to that of the intersections of the path of the ecliptic and the celestial equator' (1982: 171).

(12) A cidade Ipanoré, uma das três fundadas por Buopé, fica perto do cruzamento do Uaupés com o equador; veja também a nota anterior. 
avançou talvez meia semana contra as estações; no tempo que vem desde que a fabricação da primeira cerâmica no Uaupés avançou meses inteiros (Reichel-Dolmatoff associa os sambaquis da região, que datam de épocas ainda mais remotas, já com a observação astronômica; 1982: 180). Além disso, no sistema geral das idades do mundo, como se vê representado por exemplo nos códices mesoamericanos, metamorfoses e processos cósmicos do tipo evidente no episódio de Pinon são calculados em períodos multimilenares compatíveis com o ciclo precessional (Brotherston 1997: 373-9).

Como expressão da cultura milenar da região do Uaupés-Içana, a Leggenda de Stradelli merece análise mais detalhada. Tem uma riqueza inesperada de conhecimentos que abarcam desde o meio ambiente imediato até relatos sobre as origens vertebradas da espécie humana e uma astronomia bem elaborada. E articula estes argumentos numa narrativa bem animada, de personagens vivos, ao mesmo tempo que tem uma estrutura altamente sofisticada. Por estas e outras razões merece também comparação com os 'clássicos' da literatura indígena do continente, sobretudo a 'bíblia da América' o Popol vuh. É uma prova da dedicação e da sensibilidade de Stradelli que, neste sentido, a sua tradução não deixe de expressar tanto da inteligência dos textos originais.

\section{Referências bibliográficas}

AMORIM, A.B. de.

1928 Lendas em Nheengatú e em Portuguez. Revista do Instituto Histórico e Geographico Brasileiro, 100 (154): 3-475.

AVENI, A.; BROTHERSTON, G.

1983 Calendars in Mesoamerica and Peru. Native American Computations of Time. Oxford: BAR.

AVENI, A.; URTON, G.

1982 Ethnoastronomy and Archeoastronomy in the American Tropics. New York: New York Academy of Sciences.

BIDOU, $\mathbf{P}$.

1989 Du Mythe à la légende. La naissance de la parole dans le village des Bianacas. Journal de la Société des Américanistes, XXV: 63-90.

BOLENS, $\mathbf{J}$.

1967 Myth de Jurupari: introduction à une analyse. L'Homme, 7 (1): 50-66.

BROTHERSTON, G.

1995 Painted Books from Mexico. London: British Museum Press.

1997 La América indígena en su literatura. Mexico: Fondo de Cultura Económica.

CÂMARA CASCUDO, L. da

1967 Em Memória de Stradelli. Manaus: Governo do Estado do Amazonas.

CIVRIEUX, M. de.

1992 Watunna. Mitología makiritare. Caracas: Monte Avila.

CLOSS, $\mathrm{M}$.

1985 Native American Mathematics. Austin: Texas University Press.

HILL, J.

1993 Keepers of the Sacred Chants. Tucson: University of Arizona Press.

\section{HUGH-JONES, S.}

1979 The Palm and the Pleiades. Cambridge: Cambridge University Press.

1982 The Pleiades and Scorpius in Barasana Cosmology. Em Aveni \& Urton: 183-202.
LATHRAP, D.

1970 The Upper Amazon. London: Thames \& Hudson.

LÉVI-STRAUSS, C.

$1967 /$ Mythologiques. Paris: Seuil.

1974

NEVES, E.

1997 Paths through Dark Waters: Archaeology and indigenous history in the upper Rio Negro basin and the northwest Amazon. Bloomington: Ph.D. Thesis, Indiana University.

ORJUELA, H.H.

1983 Yurupary: mito, legenda y epopeya del Vaupés. Bogotá: Instituto Caro y Cuervo (Pub. 64).

REICHEL-DOLMATOFF, G.

1971 Amazonian Cosmos. Chicago: Chicago University Press.

1982 Astronomical Models of Social Behavior among some Indians of Colombia. Em Aveni \& Urton: 165-82.

1989 Biological and Social Aspects of the Yurupari Complex of the Colombian Vaupés Territory. Journal of Latin American Lore, 15 (1): 95-135.

1996 Yurupari. Studies of an Amazonian Foundation Myth. Cambridge: Harvard University Press

\section{RODRIGUES, J.B.}

1890 Poranduba Amazonense ou Kochyma Uara Porandub: 1872-1887. Rio de Janeiro: Leuzinger.

SÁ, L. de

1997 Reading the Rainforest. Bloomington: Indiana University.

STRADELLI, C.E.

1964 La Leggenda dell'Jurupary e outras lendas amazônicas. São Paulo: Instituto Cultural ItaloBrasileiro. Caderno 4.

UMUSIN, P.

1995 Antes o mundo não existia. Mitologia dos antigos Desana-Kehíripōrā. São João Batista do Rio Tiquié: UNIRT/ São Gabriel da Cachoeira: FOIRN. 